\title{
Intra-Cultivar Diversity in Southern Italy Olive Cultivars Depicted by Morphological Traits and SSR Markers
}

\author{
F.P. Marra, A. Marchese, G. Campisi, \\ G. Guzzetta and T. Caruso \\ Dipartimento DEMETRA \\ University of Palermo \\ Italy
}

\author{
R. Mafrica and S. Pangallo \\ Dipartimento di Gestione dei \\ Sistemi Agrari e Forestali \\ Università degli Studi Mediterranea \\ di Reggio Calabria \\ Italy
}

Keywords: Olea europaea, clonal selection, SSR, fingerprinting, germplasm

\begin{abstract}
In this study, SSR analysis was performed on a large number of putative clones of the main olive cultivars from two Italian regions, Sicily and Calabria, in order to study the genetic relatedness, and to detect any degree of genetic diversity, which can be used to unambiguously identify possible superior clones. These putative clones have been collected and observed in the last ten years, following an extensive investigation carried out in traditional olive growing areas, thanks to the reports of farmers, millers, technician, growers and nurseries. The set of microsatellite (SSR) markers used allowed the detection of the genetic diversity, resulting from somatic mutation, indicating the presence of polyclonal cultivars, or having gametic origin, indicating a seedling origin of many clones, which thus share sibling relationships. The presence of superior clones or superior genotypes is discussed.
\end{abstract}

\section{INTRODUCTION}

Southern Italy has a long tradition on olive (Olea europaea L.) cultivation and olive oil production, accounting for $37 \%$ of the Italian production. Among the Italian regions, Sicily and Calabria have a relevant place in the olive production, industry and exportation. Both regions have a very rich genetic patrimony. In these regions, the cultivation of this species is well documented since ancient times, by both archaeological and written relic sources. From the sixth century BC, the olive reached Sicily, thanks to the Phoenicians, and from this region moved to southern Italy, thanks to the Romans, who developed the grafting technology (Zohary and Hopf, 1994; Besnard et al., 2001; Rugini et al., 2011). Since the 1980s, the "Dipartimento DEMETRA" invested in research for the conservation and characterization of the main local cultivars and varieties and the regional oil production (La Mantia et al., 2005; Caruso et al., 2007; Marchese et al., 2008). In the Calabria region, the first morphological characterisation of cultivars was reported by Caruso (1883) followed by many authors (i.e., Parlati et al., 1995, 1999; Mafrica et al., 1996) and a molecular screening of Calabrian cultivars was carried out by Carriero et al. (2002) and Muzzalupo et al. (2009). In Sicily and Calabria, the main olive production is based on 17 indigenous cultivars, the most widely cultivated (Caruso et al., 2007; Mafrica et al., 1996). Often a certain amount of morphological variability has been observed within each cultivar, indicating that under the name of a single cultivar could hide a pool of different genotypes (polyclonal cultivars or cultivar-populations). The occurrence of cultivar homonymy and synonymy, the high diversity of the germoplasm and the intra-cultivar variability complicate the olive identification. As diverse morphological types have been observed in production, disease resistance, growing behaviour and fruit traits, putative clones of nine widely spread and predominantly cultivated southern Italy cultivars ('Biancolilla', 'Cerasuola', 'Moresca', 'Nocellara del Belice', 'Nocellara Messinese', 'Nocellara Etnea', 'Ogliarola Messinese' and 'Tonda Iblea', native in Sicily; 'Ottobratica' in Calabria) were analysed in this study both at the molecular level. To discriminate among olive genotypes and to study genetic relationships, DNA molecular markers, particularly microsatellites or SSRs (simple 
sequence repeats), are today widely used (reviewed in Bracci et al., 2011); therefore we employed the most outstanding set of SSRs (reviewed in Baldoni et al., 2009) to conduct our intra-clonal diversity investigation.

\section{MATERIALS AND METHODS}

An extensive and thorough investigation was conducted in traditional olive growing areas of Sicily and Calabria to identify, thanks to the reports of farmers, millers and growers, different putative clones of the main cultivars. A total of nine standard cultivars, 71 putative clones, 7 internationally grown cultivars and two landraces were analysed (Fig. 1). These comprised: 11 putative clones of 'Biancolilla', 9 of 'Cerasuola', 10 of 'Moresca', 8 of 'Nocellara del Belice', 3 of 'Nocellara Etnea', 2 'Nocellara Messinese', 5 of 'Ogliarola Messinese', 7 of 'Tonda Iblea' and 16 of 'Ottobratica'.

Genomic DNA was extracted from young leaves according to the protocol developed by Doyle and Doyle (1987).

Eight SSR primers, fluorescently labeled using four dyes 6-FAM, HEX, NED and PET, considered outstanding by the recent literature (Baldoni et al., 2009), were used: DCA:03, 05, 18 (Sefc et al., 2000); Gapu: 45, 71b, 101 (Carriero et al., 2002); EMOL (De la Rosa et al., 2002); UDO43 (Cipriani et al., 2002) (Table 1).

A UPGMA dendrogram was constructed using PowerMarker V3.25 software, based on seven SSR loci (Fig. 1), using the coefficient of similarity Nei and Li (1973). One SSR, GAPU101, was excluded from the dendrogram construction, as it amplified two loci.

\section{RESULTS AND DISCUSSION}

A quite high degree of polymorphisms was observed among the putative clones at the morphological and phenological level, confirming the observations of local farmers, millers and growers (Figs. 1 and 2).

The chosen SSR markers (DCA: 03, 05, 18; Gapu: 45, 71b; EMOL; UDO43) amplified single loci however occasionally extra alleles were observed. The primer GAPU101 amplified two loci; therefore it should be taken into account the possible elimination of that SSR marker from the list of the most useful olive primers (Baldoni et al., 2009). The number of alleles per locus varied from three with Gapu45 to twelve with UDO43 (mean=9); the observed heterozygosity was 0.78 and the PIC (Polymorphic Information Content) $=0.68$, indicating high SSR polymorphisms. SSRs were useful for detecting the genetic diversity, resulting from somatic mutation (polyclonal cultivar), or having gametic origin (cultivar population). SSRs clearly distinguished 31 accessions $(39 \%)$ on a total 80 , excluding the controls. However, the total polymorphism is even higher considering somatic mutations (up to $63 \%$ ).

As depicted by the UPGMA dendrogram (Fig. 3), many clones resulted undistinguishable at the molecular level; thus accessions also indistinguishable at the morphological level can be eliminated from our collection. Most of the Calabria putative clones of 'Ottobratica' and some putative clones of Sicilian cultivars 'Biancolilla', 'Cerasuola' and 'Nocellara del Belice' were discriminated at the molecular level and morphologically. 'Biancolilla', 'Cerasuola' and 'Ottobratica' may be considered more as landraces. Many 'Biancolilla', 'Cerasuola' and to a lesser extent 'Nocellara del Belice' putative clones shared sibling relationships, therefore they do not represent cases of intraclonal variation. Thus, this analysis enabled us to identify the somatic mutants (the true putative clones) from the siblings. Among the 'Cerasuola' putative clones, 'Cerasuola 1', 'Cerasuola 2' and 'Cerasuola Cappuccia', showing differences in their vegetative habitus, "weeping", "pillar" and "compact" respectively, resulted to be genuine somatic mutants of 'Cerasuola std'. 'Ogliarola Messinese', 'Moresca', 'Nocellara Messinese' and 'Tonda Iblea' putative clones showed differences only attributable to somatic mutation. 'Ottobratica' putative clones showed large genetic differences, which also may be due to the fact that many trees are seedlings of the 'Ottobratica std', such as 'Ottobratica Perciasacchi V.T.', 'Ottobratica Perciasacchi V.J.', 'Ottobratica promentina', 
'Ottobratica San Marco' and 'Ottobratica trovarica' (Figs. 2 and 3). The SSR profile of 'Ottobratica V.J.' was different from that of 'Ottobratica std', therefore they do not share any sibling relationship, but they represent a case of homonymy. 'Ottobratica San Pietro' showed genetic relationship with 'Ottobratica std', but looser than siblings, thus they are homonyms. 'Ottobratica Cannava tardiva', 'Ottobratica megali', and 'Ottobratica dolce' showed distinct SSR profiles than 'Ottobratica std', indicating that they are different genotypes (Figs. 2 and 3). As concern 'Ottobratica Cannava tardiva' and 'Ottobratica megali' they can be sibling.

\section{CONCLUSIONS}

The clustering of local cultivars and clones following the geographical region suggests that they share common genetic backgrounds. Our data are useful for undertaking selection of superior clones (es., 'Nocellara del Belice clone 3', has larger fruit size; Fig. 1) or individual genotypes (es., 'Ottobratica San Pietro', resistant to Antracnosis; Fig. 2). In addition this analysis allows the re-organization of our collection and to establish a core collection of the southern Italy olive germoplasm. The use of seven cultivar-controls will facilitate the SSR data comparison with other laboratories and databases.

\section{Literature Cited}

Baldoni, L., Cultrera, N.G., Mariotti, R., Ricciolini, C., Arcioni, S., Vendramin, G.G., Buonamici, A., Porceddu, A., Sarri, V., Ojeda, M.A., Trujillo, I., Rallo, L., Belaj, A., Perri, E., Salimonti, A., Muzzalupo, I., Casagrande, A., Lain, O., Messina, R. and Testolin, R. 2009. A consensus list of microsatellite markers for olive genotyping. Mol. Breed. 24:213-231. doi: 10.1007/s11032-009-9285-8.

Besnard, G., Baradat, P., Breton, C. and Khadari, B. and Berville, A. 2001. Olive domestication from structure of oleasters and cultivars using nuclear RAPDs and mitochondrial RFLPs. Genet. Sel. Evol. 33:S251-S268.

Bracci, T., Busconi, M., Fogher, C. and Sabastiani, L. 2011. Molecular studies in olive (Olea europaea L.): overview on DNA markers applications and recent advances in genome analysis. Plant Cell Rep. 30:449-462. doi: 10.1007/s00299-010-0991-9.

Carriero, F., Fontanazza, G., Cellini, F. and Giorio, G. 2002. Identification of simple sequence repeats (SSRs) in olive (Olea europaea L.). Theor. Appl. Genet. 104(23):301-307.

Caruso, G. 1883. Monografia dell'Olivo. Enciclopedia Agraria Italiana vol. III, parte V. UTET edizioni Torino, Italy.

Caruso, T., Cartabellotta, D., Motisi, A., Campisi, G., Occorso, G., Bivona, G., Cappello, A., Pane, G., Pennino, G., Ricciardo, G., Patti, M., La Mantia, M., Lain, O., Testolin, R., Finoli, C., Cacioppo, L., Corona, O., Catagnano, L., Savino, V. and Saponari, M. 2007. Cultivar di Olivo Siciliane. Identificazione Validazione, Caratterizzazione Morfologica e Molecolare e Qualità degli Oli. Contiene Manuale per la Caratterizzazione Primaria di Cultivar di Olivo Siciliane. Palermo.

Cipriani, G., Marrazzo, M.T., Marconi, R., Cimato, A. and Testolin, R. 2002. Microsatellite markers isolated in olive are suitable for individual fingerprinting and reveal polymorphism within ancient cultivars (Olea europaea L.). Theor. Appl. Genet. 104:223-228.

De la Rosa, R., James, C.M. and Tobutt, K.R. 2002. Isolation and characterization of polymorphic microsatellites in olive (Olea europaea L.) and their transferability to other genera in the Oleaceae. Mol. Ecol. Notes 2:265-267.

Doyle, J.J and Doyle, J.L. 1987. A rapid DNA isolation procedure for small quantities of fresh leaf tissue. Phytochem. Bull. 19:11-15.

La Mantia, M., Lain, O., Caruso, T. and Testolin, R. 2005. SSR-based DNA fingerprints reveal the genetic diversity of Sicilian olive (Olea europaea L.) germplasm. J. Hortic. Sci. Biotech. 80:628-632.

Mafrica, R., Zappia, R. and Continella, G. 1996. Indagine preliminare sul germoplasma di 
olivo nell'area grecanica della provincia di Reggio Calabria. Atti III Giornate Scientifiche SOI, Erice (TP), Italy, March 10-14.

Marchese, A., Costa, F., Marra, F.P., Campisi, G., Cutuli, M., Ricciardo, P., Tobutt, K.R. and Caruso, T. 2008. Determination of intra-cultivar variation among Sicilian olive germplasm by using microsatellite markers. VI International Symposium on Olive Growing. Resumos, Evora, Portugal, September 9-13, p.67.

Muzzalupo, I., Stefanizzi, F. and Perri, E. 2009. Evaluation of olives cultivated in southern Italy by SSR markers. HortScience 44:582-588.

Parlati, M.V., Perri, E., Rizzuti, B. and Palopoli, A. 1995. Selezione dell'olivo in Calabria clone "Carolea Cefaly": un interessante clone caratterizzato da precocità di maturazione e pezzatura del frutto superiore alla media. Atti del Convegno "L'Olivicoltura mediterranea: stato e prospettive della coltura e della ricerca". Rende, Italy, January 26-28.

Parlati, M.V., Perri, E., Rizzuti, B. and Pellegrino, M. 1999. Caratterizzazione della cv. Pennulara o Nostrale di Caccuri: ecotipo interessante per le caratteristiche carpologiche e qualitative dell'olio. Atti $5^{\circ}$ Convegno Nazionale sulla Biodiversità. Caserta, Italy, September 9-10.

Rugini, E., De Pace, C., Gutierrez-Pesce, P. and Muleo, R. 2011. Olea. In: K. Chittaranjan (ed.), Wild Crop Relatives: Genomic and Breeding Resources, $1^{\text {st }}$ Edn. Springer, p.79117.

Sefc, K.M., Lopes, M.S., Mendonça, D., Rodrigues Dos Santos, M., Laimer Da Câmara Machado, M. and Da Câmara Machado, A. 2000. Identification of microsatellite loci in olive (Olea europaea) and their characterization in Italian and Iberian olive trees. Mol. Ecol. 9:1171-1173.

Zohary, D. and Hopf, M. 1994. Domestication of Plants in the Old World. $2^{\text {nd }}$ ed. Clarendon Press, Oxford. 


\section{Figures}

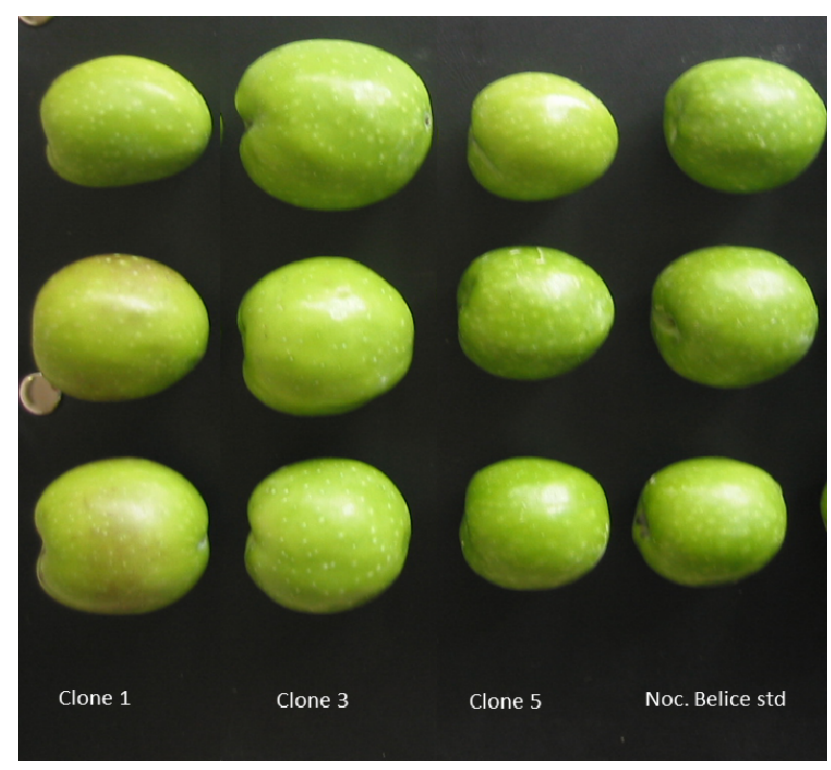

Fig. 1. Fruit morphological variability of some 'Nocellara del Belice' clones.
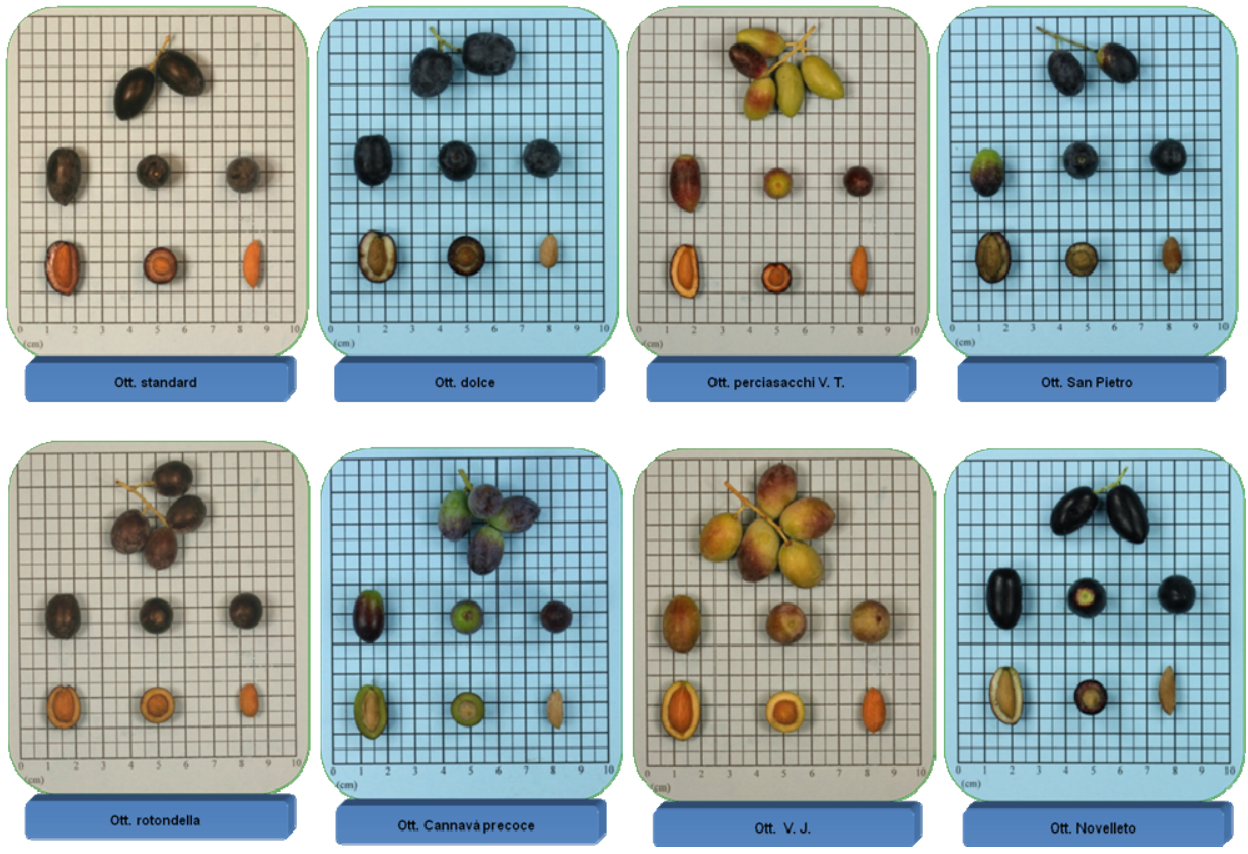

Fig. 2. Morphological variability of seven 'Ottobratica' putative clones, confirming the high level of intra-cultivar variation detected at the genetic level. 


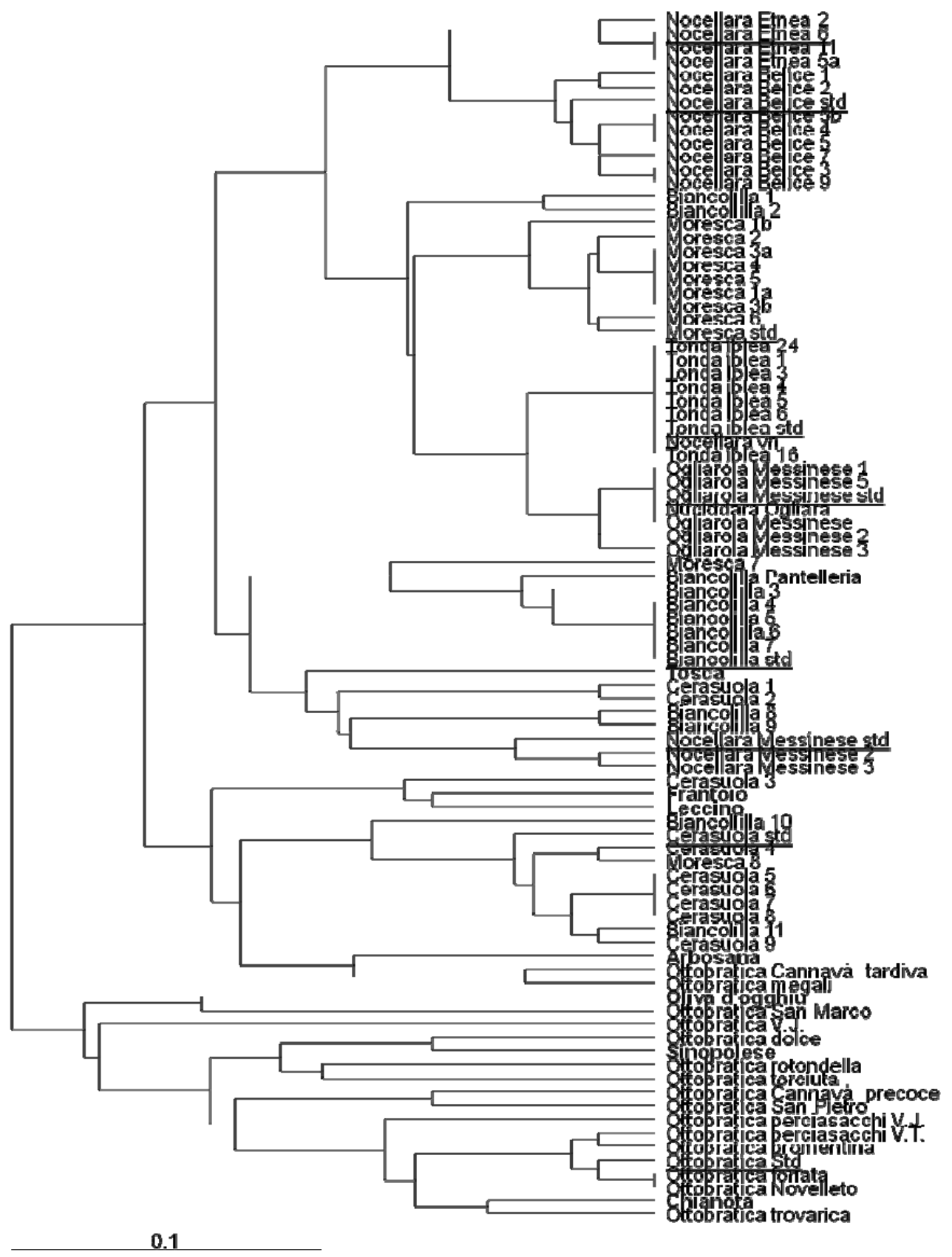

Fig. 3. UPGMA dendrogram based on eight SSRs showing relationships and identities between 71 putative clones. Underlined = cultivars standard. Bold = cultivars used as controls. 